\title{
RELATIONSHIP BETWEEN SECONDARY METABOLITES, ANTIRADICAL ACTIVITIES, AND COLOUR CHARACTERISTICS OF COCHLOSPERMUM TINCTORIUM A. RICH. (BIXACEAE) ROOT
}

\author{
C. J. Ndouyang, G. Kaptso, R. M. Nguimbou, J. Scher, C. Gaiani And B. Facho \\ (C. J. N.: Université de Pala, Tchad; G. K. \& R. M. N: Department des Sciences Alimentaires et \\ Nutrition, ENSAI, Université de Ngaoundéré, B.P. 455 Ngaoundéré, Cameroun; J. S. \& C. G.: \\ Laboratoire d'Ingénierie des Biomolécules (LIBios), Nancy-University, 2 avenue de la Forêt de \\ Haye B.P. 172 F-54505 Vandoeuvre-lès-Nancy, France; B. F.: Département de Biologie, Faculté \\ des Sciences Exactes et Appliquées, Université de N’Djaména, B.P. 1027 N’Djaména, Tchad). \\ *Corresponding author's email: ndouyang@yahoo.fr
}

\begin{abstract}
Cochlospermum tinctorium A. Rich. (Bixaceae) is a widespread herbaceous plant in the African sahelian and soudanian zones. Its root is used as food and medicinal plant. Studies of secondary metabolites, functional activities and trichromatic parameters were realized according to standard methods of laboratory. At a threshold of $\alpha=0.05$, significant correlations $(p<0.05)$ were found between secondary metabolites contents and functional activities such as radical scavenging activity of antioxidant component or hydroxyl radical scavenging activity. The value of DPPHH was $95.56 \pm 0.94 \%$ for CT inner Matrix with variation of $0.12 \%$ for CT Soaked inner Matrix and $1.63 \%$ for CT Peeler. But HSRA was $37.14 \pm 5.71$ for CT inner Matrix with variation of $-38.46 \%$ for CT Soaked inner Matrix and $-71.79 \%$ for CT Peeler. Cochlospermum tinctorium root has exhibited efficiency to heal many diseases thanks to multiple bioactive compounds. In addition, the colour of powders depended upon chemical compounds. Finally, Cochlospermum tinctorium root was found to neutralize organic radicals and reactive oxygen species.
\end{abstract}

\section{Introduction}

Bixaceae, usually represented by Bixa orellana L., Cochlospermum planchonii Hook. F. and Cochlospermum tinctorium A. Rich., is a wellknown plant family in herbal medicine. The species Cochlospermum tinctorium A. Rich., the plant of interest in this study is widely distributed in the savannah area of Western and Central Africa. A recent study has shown that the plant has hepatoprotective effect against carbon tetrachloride induced toxicity in rats (Etuk et al., 2009b). However, a number of medicinal plants have been recommended for the treatment of liver disorders (Sanmugapriya \& Venkataraman, 2006). Apart from the preventive actions, drugs are also needed for the treatment of existing pathological conditions (Tiné et al,. 1993; Zhang et al., 2013). According to many authors, the root of Cochlospermum tinctorium (also called rhizome) is used in the prevention or treatment of malaria (Benoit et al., 1995; Guiguemde et al., 2000; Zederkopff-Ballin et al., 2002; Ahmadu et al., 2014), bacterial diseases (Ouattara et al., 2007; 
Tidjani et al., 2009; Magaji et al., 2010), hepatic affections such as jaundice, chronic hepatitis B (Etuk et al., 2009a; Akinloye et al., 2011; Akinloye et al., 2012; Musa et al., 2012). It is also used in controlling physiological disorders such as hyperglycemia (Ndouyang et al., 2018), convulsion (Maiha et al., 2009), inflammation and pain (Nergard et al., 2005; Ahmed et al., 2011). In addition, the root of plants of the genus Cochlospermum used against viruses was also reported (Solon et al., 2012; Musa et al., 2012). In accordance with this view, rhizomes of Cochlospermum tinctorium are used against fever, hepatitis, abdominal pain, helminthes and bilharzias infestations (Ekanem, 1994). The root of C. tinctorium contains chemicals that are efficient against many diseases and its extracts are used as antidote when intoxication by other medicinal plants occur (Musa et al., 2012). The factors of hepatic diseases are multiple and developing a single agent capable of preventing hepatic diseases at all times appears elusive. Finding a potent drug that can regenerate hepatic functions irrespective of the initial cause of the damage appears more feasible by using $\mathrm{C}$. tinctorium (Etuk et al., 2009a, 2009b). There are no reliable curative drugs for the treatment of hepatic diseases in modern medicine. The efficacies of most of these medicinal plants have to be validated. So, investigations of medicinal plants with potential hepatic regenerative activity are important. The present study examined the ability of the functional activities of C. tinctorium root extract against free radicals.

\section{Experimental}

\section{Plant material and drying}

The plant materials, the fresh roots of Cochlospermum tinctorium were collected in the village of Mindaore (local name of the plant in
Tupuri language: 'Belyewn'), at the Eastern of the region of Mayo-Kebbi in Chad. The sample was taken to the Laboratory of Biophysics, Food Biochemistry and Nutrition of ENSAI/ University of Ngaoundere Cameroon for unit operations by using separately two different processing as reported by Ndouyang et al. (2018). The cuticle was discarded, and the first operation being a traditional household process consisted of reducing the inner matrix of the root in slices and of dividing the skin of the same root in small pieces; the second involved soaking processing of a part of the root inner matrix. Here, root slices of known weights $(100-150 \mathrm{~g})$ were subject to soaking twice in $5 \mathrm{~L}$ of water for $3 \mathrm{~h}$ before replacing tap water. After all the pretreatments, the samples were dried at $50^{\circ} \mathrm{C}$ for $18 \mathrm{~h}$, and ground into powder, before storage at $4^{\circ} \mathrm{C}$ for different analysis.

\section{Determination of secondary metabolites}

The secondary metabolites in the $C$. tinctorium root considered in this respect are the following ones: total phenolic compounds; flavonoids; total, condensed and hydrolysable tannins; total and soluble oxalates; phytates, and total cyanides. Their contents were determined as using methods reported by Ndouyang et al. (2015).

\section{Alkaloids determination}

The alkaloid content was determined gravimetrically (Haborne, 1973), which was recently used by Adeniyi et al. (2009). $5 \mathrm{~g}$ of each sample was weighed using a weighing balance and dispersed into $50 \mathrm{~mL}$ of $10 \%$ acetic acid solution in ethanol. The mixture was well shaken and then allowed to stand for about $4 \mathrm{~h}$ before it was filtered. The filtrate was then evaporated to one quarter of its original volume on hot a plate. Concentrated ammonium hydroxide was added drop wise in order to precipitate the alkaloids. A pre-weighed filter paper was used to 
filter off the precipitate and it was then washed with $1 \%$ ammonium hydroxide solution. The filter paper containing the precipitate was dried in an oven at $60^{\circ} \mathrm{C}$ for $30 \mathrm{~min}$, transferred into desiccators to cool and then reweighed until a constant weight was obtained. The constant weight was recorded. The weight of the alkaloid was determined by weight difference of the filter paper and expressed as a percentage of the sample weight analyzed. The experiment was repeated three times for each food stuff sample and recorded as the average of three replicates.

\section{Determination of flavonoids}

Flavonoids content of the different samples was determined following the method of Eom et al. (2007). Essentially, $1 \mathrm{~g}$ of each ground sample was homogenized with $20 \mathrm{~mL}$ of extracting solvent (methanol/water/acetic acid, $140 / 50 / 10, \mathrm{v} / \mathrm{v}$ ) and filtered into volumetric flasks and its volume was adjusted to $100 \mathrm{~mL}$ by addition of extracting solvent. Aliquots of $2.5 \mathrm{~mL}$ were transferred into $50 \mathrm{~mL}$ volumetric flasks and their volumes made up of water (analyzed solutions). To each $10 \mathrm{~mL}$ of analyzed solution, $2 \mathrm{~mL}$ of water and $5 \mathrm{~mL}$ of $\mathrm{AlCl} 3 \mathrm{re}$ agent (133 mg crystalline aluminum chloride and $400 \mathrm{mg}$ crystalline sodium acetate were dissolved in $100 \mathrm{~mL}$ of extracting solvent) were added. The absorbance was recorded at $430 \mathrm{~nm}$ against a blank made of $10 \mathrm{~mL}$ of analyzed solution and $5 \mathrm{~mL}$ of water. The amount of flavonoids was calculated from the calibration curve of quercetin standard solutions and expressed as mg quercetin/100 $\mathrm{g}$ of plant material.

\section{Determination of carotenoids content}

In addition, determination of total carotenoids and chlorophylls a and b methanolic solutions of sample extracts of the appropriate concentration (1.0 to $4.0 \mathrm{mg} / \mathrm{mL})$ were analyzed in a visible spectrophotometer (UV/Vis SP8001 Spectrophotometer, Axiom, Germany) at 470, 653 and $666 \mathrm{~nm}$. The concentrations of carotenoids and chlorophylls $\alpha$ and $\beta$ were determined according to the equations of Lichtentha and Wellburn reported recently by Rainha et al. (2011) as follows:

Total carotenoids $(\mathrm{mg} / \mathrm{L})=1000 \mathrm{Abs} 470-2.860 \mathrm{Ca}-129.2$ $\mathrm{Cb} / 245$,

Chlorophyll a Ca (mg/L) $=15.65$ Abs666 - 7.340 Abs653

Chlorophyll b Cb (mg/L) = 27.05 Abs653 - 11.21 Abs666.

\section{$D P P H$ radical scavenging activity}

The 1,1-diphenyl-2-picryl-hydrazyl (DPPH) is a stable free radical and is widely used to assess the radical scavenging activity of antioxidant. This method is based on the reduction of DPPH in methanol solution in the presence of a hydrogen donating antioxidant due to the formation of the non-radical form, DPPH-H. The free radical scavenging activity of all the extracts was evaluated by DPPH according to the previously reported method (Sakthidevi \& Mohan, 2013). Briefly, an $0.1 \mathrm{~mm}$ solution of DPPH in methanol was prepared, and $1 \mathrm{~mL}$ of this solution was added to $3 \mathrm{~mL}$ of the solution of all extracts in methanol at different concentration $(125,250,500 \& 1000 \mu \mathrm{g} / \mathrm{mL})$. The the absorbance was measured at $517 \mathrm{~nm}$ using a UV-VIS spectrophotometer (UV/Vis SP8001 Spectrophtometer, Axiom, Germany). Lower absorbance values of reaction mixture indicate higher free radical scavenging activity. Trolox was used as positive control. All the tests were performed in triplicates and the results were averaged. The capability to scavenging the DPPH radical or DPPH scavenging effect was calculated by using the following formula: 


$$
\text { DPPH.H(\%) }=\frac{A_{\text {control }}-A_{\text {essay }}}{A_{\text {control }}} * 100
$$

HydroxylRadical Scavenging Activity(HRSA): The antioxidant activity of extracts was also measured as their ability to inhibit non site-specific hydroxyl radical-mediated peroxidation following the method reported by Abdou Bouba et al. (2010). The reaction mixture used, contained $100 \mu \mathrm{L}$ of extract dissolved in distilled water, $500 \mu \mathrm{L}$ of $5.6 \mathrm{mM}$ 2-deoxy-D-ribose in $\mathrm{KH} 2 \mathrm{PO} 4-\mathrm{NaOH}$ buffer $(50 \mathrm{mM}, \mathrm{pH}$ 7.4), $200 \mu \mathrm{L}$ of premixed $100 \mu \mathrm{M} \mathrm{FeCl} 3$ and $104 \mathrm{mM}$ EDTA $(1: 1 \mathrm{v} / \mathrm{v})$ solution, $100 \mu \mathrm{L}$ of $1.0 \mathrm{mM} \mathrm{H} 2 \mathrm{O} 2$ and $100 \mu \mathrm{L}$ of $1.0 \mathrm{mM}$ aqueous ascorbic acid. Tubes were vortexed and incubated at $50^{\circ} \mathrm{C}$ for $30 \mathrm{~min}$. After this, $1 \mathrm{~mL}$ of $2.8 \%$ TCA and $1 \mathrm{~mL}$ of $1.0 \%$ TBA was added to each tube and the samples vortexed and heated in a water bath at $50^{\circ} \mathrm{C}$ for $30 \mathrm{~min}$. The extent of oxidation was estimated from the absorbance of the solution at 532 $\mathrm{nm}$. The percentage inhibition values were calculated from the absorbance of the control (Acontrol) and of the sample (Asample) using equation where the controls contained all the reaction reagents except the extract or positive control substance. The antioxidant activities of the extracts were expressed as mannitol equivalents (mg mannitol/g extract) as followed:

$$
\operatorname{HRSA}(\%)=\frac{A_{\text {control }}-A_{\text {sample }}}{A_{\text {control }}}
$$

Ferric Iron Reducing Activity (FIRA) The antioxidant potential of the different sample extracts was also evaluated by their ability to reduce iron-(III) to iron-(II) following the method of Oyaizu (1986). In this respect, $1 \mathrm{~mL}$ aliquot of each extract, dissolved in distilled water, was mixed with $2.5 \mathrm{~mL}$ of phosphate buffer $(0.2 \mathrm{M}, \mathrm{pH} 6.6)$ and $2.5 \mathrm{~mL}$ of a $1 \%$ aqueous $\mathrm{K} 3 \mathrm{Fe}(\mathrm{CN}) 6$ solution and incubated for $30 \mathrm{~min}$ at $50{ }^{\circ} \mathrm{C}$. After this, $2.5 \mathrm{~mL}$ of $10 \%$ TCA was added, and the mixture centrifuged for $10 \mathrm{~min} .2 .5 \mathrm{~mL}$ aliquot of the supernatant was mixed with $2.5 \mathrm{~mL}$ of distilled water and $0.5 \mathrm{~mL}$ of $0.1 \%$ aqueous $\mathrm{FeCl} 3$, and the absorbance at $700 \mathrm{~nm}$ was recorded. Ferric iron reducing activity was determined as ascorbic acid equivalents (mg ascorbic acid/g extract).

Measurement of colour characteristics $L^{*}, a^{*}$ and $b^{*}$

Colour measurements of three samples were carried out using a portable tintometer (Lovibond RT Colour Measurement Kit V2.28) with a $10^{\circ}$ observer window and a D-65 light source as recently purchased by Abdou Bouba et al. (2012). The colour values generated by the equipment were expressed as $\mathrm{L}^{*}$ (whiteness or darkness), $\mathrm{a}^{*}$ (redness/greenness) and $\mathrm{b}^{*}$ (blueness/yellowness). The whiteness index (WI) was calculated by the following formula (Tsai, 1994):

$$
W I=100-\sqrt{(100-L)^{2}+a^{2}} .
$$

\section{Calculation of variation}

The variations $(\Delta)$ of chemical compounds, colour and functional activities parameters of CTSM (C. tinctorium) and CTP (C. tinctorium) were evaluated as follows (Sonnergaard, 1999):

$$
\Delta_{1,2}(\%)=\frac{\text { Value } 2-\text { Value } 1}{\text { Value } 1} * 100
$$

Value 2: analyzed value from CTSM or CTP; value 1: analyzed value from CTM only. 


\section{Statistical Analysis}

Analyses were performed in triplicate for chemicals, and colour measurement was repeated up to five times. The software Statgraphics Plus 5.0 was used for the statistical analysis at a threshold, $\alpha=0.05$. Principal component analysis and Pearson correlation was done using the Statbox 6.4 statistical software (Paris, France).

\section{Secondary metabolites}

\section{Results}

The compared study of secondary metabolites (Fig. 1) contained in the three powders of $\mathrm{C}$. tinctorium (CT), namely CT Matrix (CTM), CT Soaked Matrix (CTSM) and CT Peeler or skin (CTP), revealed variable secondary metabolites contents. The total phenolic compounds or phenols are present in all the samples. How- ever, CTM has a higher phenolic content than CTSM and CTP. Tannins and hydrolysable tannins, in particular, constitute important phenolic compounds in the root of $\mathrm{C}$. tinctorium. Followed by phytates and oxalates that are mainly accumulated in the peeler or skin of C. tinctorium (CTP). Compared to CTM, the variation $(\Delta)$ of oxalate content was $30.46 \%$ for CTSM and $70.71 \%$ for CTP in the C. tinctorium root (Table 1). But oxalates were reduced from CTM and had oxalate content very low in CTSM $(\Delta=-47.01 \%)$. The phenolic compounds $(\Delta=-49.28 \%)$, including tannins $(\Delta=$ $-29.06 \%$ ), were washable by soaking $C$. tinctorium root slices. Contrary, phytates were not washable $(\Delta=-74.20 \%)$ in the conditions of the present study.

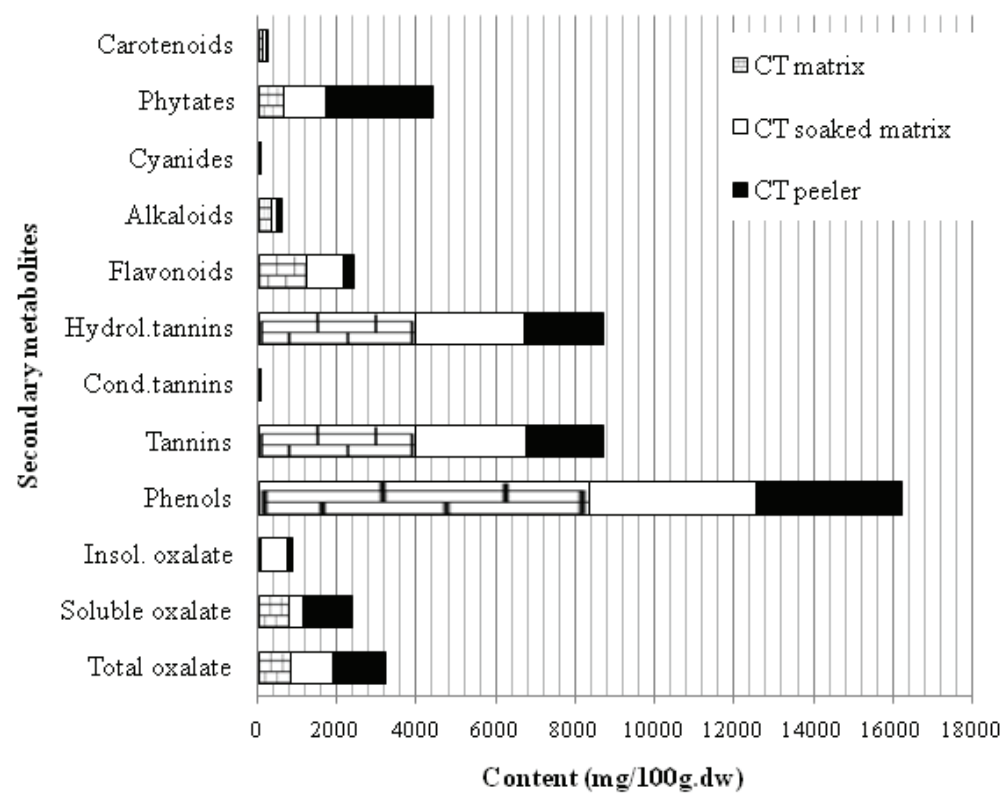

Fig. 1: Comparison of secondary metabolites content in different part of C. tinctorium root Insol = insoluble; cond $=$ condensed; hydrol $=$ hydrolysable 


\section{Functional activities}

The three functional activities of the C. tinctorium root extracts were more or less based on the samples (Fig. 2). The antioxidant power revealed by DPPH', was important in each sample. At $5 \%$ of threshold, no statistical significant difference was detected $(\mathrm{p}>0.05)$. However, appreciable values of anti-hydroxyl radical activities (HRSA) were detected at a high level for CTM, an intermediate level for CTSM and a low level for CTP. That can be explained by the presence of high activity compounds against $\mathrm{OH}^{*}$ in the root of $C$. tinctorium (CTM). In these conditions, $C$. tinctorium root presented no significant activity nor power of reducing ferric iron $\left(\mathrm{Fe}^{3+}\right)$ in ferrous iron $\left(\mathrm{Fe}^{2+}\right)$. The three values (for CTM, CTSM and CTP) stayed at less than $15 \%$. Thus, Table 1 shows, for DPPH test, a low variation at the same time for CTSM $(\Delta=0.12 \%)$ and CTP $(\Delta=1.63 \%)$. These results revealed that the three samples have the same antioxidant power with no statistical significant difference $(p>0.05)$. In view of this evidence, the whole root of $C$. tinctori$u m$ can be considered as more efficient against organic radicals like $\mathrm{DPPH}^{\circ}$. Meanwhile, variation for HRSA were important for CTSM $(\Delta$ $=-38.46 \%)$ and for CTP $(\Delta=-71.79 \%)$. There was a significant difference $(\mathrm{p}<0.05)$ in terms of activity against hydroxyl $\mathrm{OH} \bullet$.

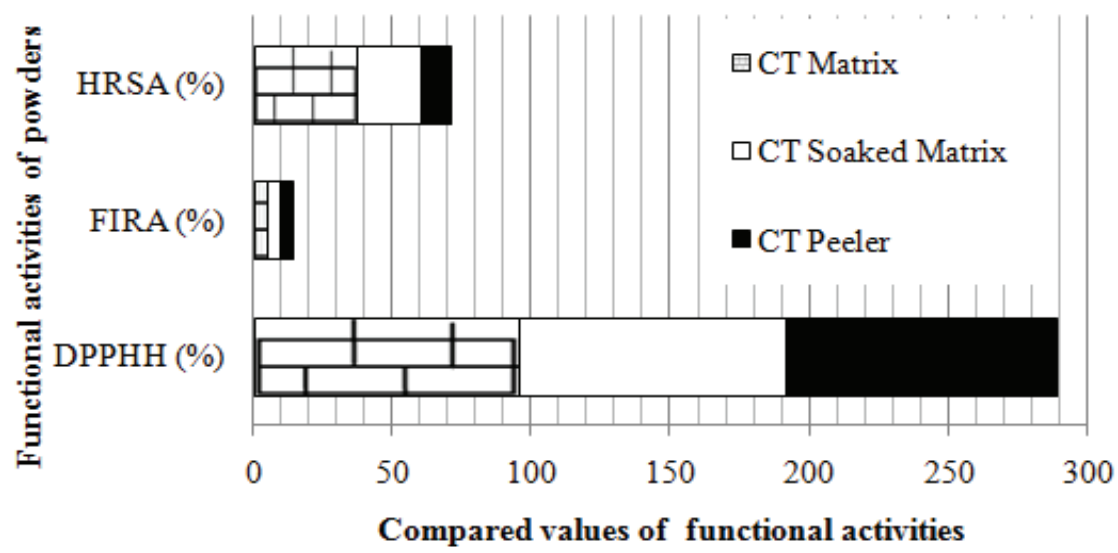

Fig. 2: Comparison of functional activities values of different part of $\mathrm{C}$. tinctorium root DPPH = 1,1-diphenyl-2-picrylhydrazyl; FIRA = Ferric Iron Reducing Activity; HRSA = Hydroxyl Radical Scavenging Activity.

\section{Colours}

The three parameters that are in the trichromatic system are designed by the balance $\mathrm{L}^{*}$ (Luminance/darkness), a* (redness/greenness), $\mathrm{b}^{*}$ (blueness/yellowness), and their combination or whiteness index (WI) are presented in Fig. 3. All the values for the balance L* (lumi- nance/darkness) were almost unique, but have remained low than the reference value. Also, no statistical difference was observed between samples for the balance $a^{*}$ (redness/greenness). Their respective WI were lower than reference value. So, Table 1 shows, for values reported to the CTM ones, variation of $-1.32 \% \mathrm{~L}^{*}$ for 
CTSM attesting of effect of soaking on this ation was observed $(p>0.05)$, but the others balance, and variation of $-0.20 \% b^{*}$ for CTP. cases revealed significant difference $(p<0.05)$. In the two cases, no statistical significant vari-

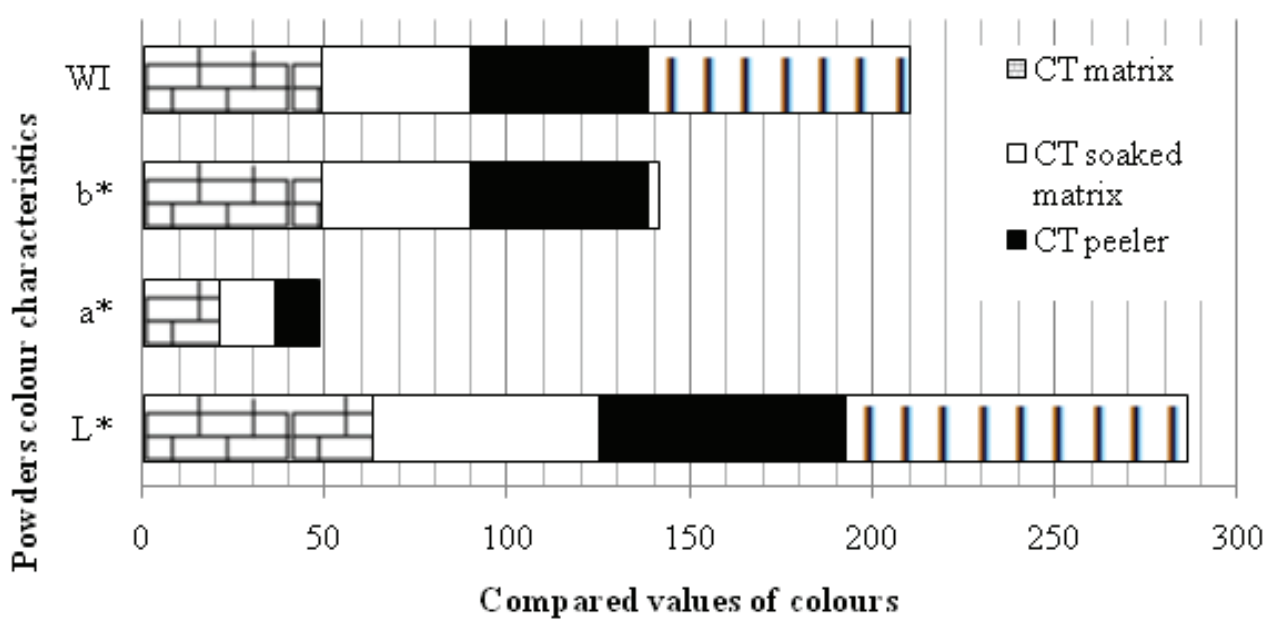

Fig. 3: Comparison of colour characteristics of different part of $\mathrm{C}$. tinctorium root $\mathrm{L}^{*}=$ balance luminance/darkness; $\mathrm{a}^{*}=$ balance redness/greenness; $\mathrm{b}^{*}=$ blueness/yellowness; $\mathrm{WI}=$ Whiteness index.

At the end of the presentation of the results, it appears necessary to look for correlation between variables in order to lead a structured discussion. 
TABLE 1

Variation of mean values of parameters of CTSM and CTP linked to CTM ones

\begin{tabular}{|c|c|c|c|}
\hline \multirow[b]{3}{*}{ Variables } & & \multirow{2}{*}{\multicolumn{2}{|c|}{$\begin{array}{l}\text { Variation of mean values } \\
\text { linked to CTM ones }(\Delta, \%)\end{array}$}} \\
\hline & & & \\
\hline & CTM & CTSM & CTP \\
\hline Total oxalate (mg/100g.dw) & $799.81 \pm 31.99$ & 30.46 & 70.71 \\
\hline Soluble oxalate $(\mathrm{mg} / 100 \mathrm{~g} . \mathrm{dw})$ & $739.38 \pm 30.81$ & -47.01 & 65.92 \\
\hline Insoluble oxalate (mg/100g.dw) & $60.43 \pm 1.18$ & 978.26 & 129.24 \\
\hline Phenols (mg/100g.dw) & $8327.76 \pm 389.96$ & -49.28 & -56.11 \\
\hline Tannins (mg/100g.dw) & $3929.48 \pm 177.72$ & -29.04 & -50.11 \\
\hline Condensed tannins (mg/100g.dw) & $1.50 \pm 0.40$ & 12.66 & -89.86 \\
\hline Hydrolysable tannins (mg/100g.dw) & $3927.98 \pm 177.53$ & -29.06 & -50.09 \\
\hline Flavonoids (mg/100g.dw) & $1193.30 \pm 32.07$ & -21.75 & -79.10 \\
\hline Alkaloids (mg/100g.dw) & $305.97 \pm 15.26$ & -59.38 & -56.45 \\
\hline Cyanides (mg/100g.dw) & $0.33 \pm 0.05$ & 112.76 & 135.67 \\
\hline Phytates (mg/100g.dw) & $622.84 \pm 132.80$ & 74.20 & 328.21 \\
\hline Carotenoids (mg/100g.dw) & $113.11 \pm 12.86$ & -26.86 & -84.45 \\
\hline DPPH (\%) & $95.56 \pm 0.94$ & 0.12 & 1.63 \\
\hline FIRA (\%) & $4.57 \pm 0.10$ & 1.26 & -0.09 \\
\hline HRSA (\%) & $37.14 \pm 5.71$ & -38.46 & -71.79 \\
\hline $\mathrm{L}^{*}$ & $62.91 \pm 0.29$ & -1.32 & 6.80 \\
\hline$a^{*}$ & $20.81 \pm 0.22$ & -26.80 & -43.87 \\
\hline$b^{*}$ & $48.88 \pm 0.31$ & -16.33 & -0.20 \\
\hline WI & $35.20 \pm 0.44$ & 19.81 & 13.78 \\
\hline
\end{tabular}

\section{Discussion}

The antioxidant activity, the anti-hydroxyl radical activity or the ferric iron reduction activity were linked to specific secondary metabolites of C. tinctorium root. Besides, the trichromatic system $\left(\mathrm{L}^{*}, \mathrm{a}^{*}, \mathrm{~b}^{*}\right)$ was the fact of specific compounds.

The correlation study (Table 2), shows an association between metabolites and functional activities or trichromatic balance. At $\mathrm{p}<0.05$, the antioxidant activity or scavenging capacity of radical 1,1-diphenyl-2-picrylhydrazyl $(\mathrm{DPPH} \bullet)$ was significantly correlated to soluble oxalates and phytates contents $(r=0.709$ to $0.735)$, and in a non-significant correlation, to cyanides content $(r=0,581)$. However, these activities appeared not associated to phenolic compounds (hydrolysable tannins, flavonoids) and carotenoids $(\mathrm{r}=-0.816$ to -0.719$)$. 
Meanwhile, HRSA appeared highly correlated to phenolic compounds (including hydrolysable tannins, flavonoids), alkaloids and carotenoids ( $r=0.840$ to 0.957 ). Contrarily, the secondary metabolites without anti-hydroxyl activity were hydolysable oxalates, cyanides and phytates ( $\mathrm{r}=-0.972$ to -0.857$)$.

Phenolics are secondary metabolites that play a role in the maintenance of the human body. The presence of phytoconstituents, such as phenols, flavonoids and tannin in plants, indicates the possibility of antioxidant activity and this activity helps in preventing a number of diseases through free radical scavenging activity. Therefore, phenolic compounds are antioxidant agents that scavenge free radicals responsible of oxidative damage. Recently, Sakthidevi and Mohan (2013) reported that phenolic compounds have attracted much interest recently because in vitro studies suggest that they have a variety of beneficial biological properties like anti-inflammatory, antitumor and antimicrobial activities. Studies have found that antioxidant properties are due to the presence of phenols and flavonoids (Jose \& Radhamany, 2012). Antioxidant activity of phenolic compounds is based on their ability to donate hydrogen atoms to free radicals. In addition, they possess ideal structural properties for free radical scavenging properties. Flavonoids are important secondary metabolites of plant modulating lipid peroxidation involved in atherogenesis, thrombosis and carcinogenesis. It has been confirmed that pharmacological effects of flavonoids is correlating with their antioxidant activities (Mbaebie et al., 2012). Free radicals and other reactive species are thought to play an important role in many human diseases. Radical scavenging activities are very important due to the deleterious role of free radicals in biological systems.

Many authors have reported activities of $\mathrm{C}$. tinctorium to protect liver against intoxication or affectation (Sanmugapriya \& Venkataraman, 2006; Etuk et al., 2009a, 2009b), even infection by viruses (Solon et al., 2012; Musa et al., 2012). Nowadays, it is well known that phenolic compounds are highly responsible for the health effects derived from consumption of plant origin food (Villaño et al., 2007). According to these authors, phenolic compounds play a key role as antioxidants due to the presence of hydroxyl substituents and their aromatic structure, which enables them to scavenge free radicals. They attested these reactions:

$\mathrm{ArOH}+\mathrm{DPPH}^{\circ} \rightarrow \mathrm{ArO}^{\circ}+\mathrm{DPPH}-\mathrm{H}$

$\mathrm{ArO}^{\circ}+\mathrm{DPPH}^{\circ} \rightarrow$ products

The reaction [i] indicates that

$$
-\frac{d\left[D P P H^{\bullet}\right]}{d t}=n k_{1}\left[D P P H^{\bullet}\right][\mathrm{ArOH}]
$$

where $\mathrm{n}$ is the stoichiometric factor pf $\mathrm{ArOH}$. Vegetal compound react with radical DPPH• by giving proton $\mathrm{H}$ to reduce $\mathrm{DPPH} \bullet$ into DPPHH (Zhang \& Yasumori, 2004). The significant positive correlation between HRSA and metabolites such as aromatic compounds and the phytoenes (phenolic compound including tannins and flavonoids, alkaloids, carotenoids) show effective antioxidant reactions. Meanwhile, they are efficient against reactive oxygen species (ROS) such as $\mathrm{OH} \bullet$ by establishing single or multiple chemical bonds to produce water in some cases. However, as asserted by Bouba et al., 2010), the C. tinctorium root extracts have shown ability to inhibit non site-specific hydroxyl radical-mediated peroxidation. Hydroxyl radicals $\mathrm{OH} \bullet$ react with oxalates, cyanides, and phytates, compounds that are in their neutral forms in acid medium and anions when the medium is basic. These chemicals are involved in antioxidant activities but do not neutralize organic radicals comparable to $\mathrm{DPPH} \bullet$. Thus, C. tinctorium root extracts are 
potent and reduce both organic and non-specific radicals chemically similar to DPPH• and $\mathrm{OH} \bullet$. Its uses as medicinal root for treatment of many diseases, is based on its multiple capacities in healing or correcting organic affections (Etuk et al., (2009a, 2009b)). Cellular damages in rats were healed by consumption of $\mathrm{C}$. tinctorium root extracts. The cellular regeneration are enhanced by the $\mathrm{C}$. tinctorium root extracts. According to Auldridge et al. (2006), apocarotenoids are responsible of cellular regeneration. Nowadays, cochloxanthine and dihydrocochloxanthine are two principles apocarotenoids recognize in the $\mathrm{C}$. tinctorium root (Akinloye et al., 2012; Musa et al., 2012).
If FIRA has no significant correlation with a secondary metabolite of $\mathrm{C}$. tinctorium root extract, it would be linked to the lower reductor content such as vitamin $\mathrm{C}$ or citric acid. Lastly, the values of trichromatic system parameters $\left(\mathrm{L}^{*}, \mathrm{a}^{*}, \mathrm{~b}^{*}\right)$ were also correlated to phytochemical compounds. The balance L* (luminance/darkness) is significantly associated to oxalates ( $\mathrm{r}=0.816$ to 0.949$)$ and to phytates (0.913); they are anions that give white powders. The balance $\mathrm{a}^{*}$ (redness/greenness) is correlated with aromatic compounds and/or phytoenes phenols including tannins and flavonoids, alkaloids, carotenoids ( $r=0.897$ to 0.989$)$. Finally, the balance $b^{*}$ (blueness/yellowness) is correlated to just hydrolysable tannins $(r=0.806)$.

TABLE 2

Pearson matrix of correlation between colours and secondary metabolites (mg/100 g.dw) in C. tinctorium root.

\begin{tabular}{llllllll}
\hline & DPPHH & FIRA & HRSA & & & \\
\multicolumn{1}{c}{ Variables } & $(\%)$ & $(\%)$ & $(\%)$ & $L^{*}$ & $a^{*}$ & $b^{*}$ & WI \\
\hline Total oxalate & $\mathbf{0 . 7 3 5}$ & -0.076 & $\mathbf{- 0 . 9 7 2}$ & $\mathbf{0 . 8 1 6}$ & $\mathbf{- 0 . 9 7 1}$ & 0.074 & 0.609 \\
Soluble oxalate & $\mathbf{0 . 7 0 9}$ & -0.164 & -0.540 & $\mathbf{0 . 9 4 9}$ & -0.471 & $\mathbf{0 . 8 0 6}$ & -0.204 \\
Insol. oxalate & -0.275 & 0.147 & -0.157 & -0.518 & -0.246 & $\mathbf{- 0 . 9 9 0}$ & $\mathbf{0 . 8 0 8}$ \\
Phenols & -0.581 & -0.114 & $\mathbf{0 . 8 7 5}$ & -0.461 & $\mathbf{0 . 9 5 7}$ & 0.408 & $\mathbf{- 0 . 9 1 2}$ \\
Tannins & $\mathbf{- 0 . 7 1 7}$ & -0.079 & $\mathbf{0 . 9 3 2}$ & $\mathbf{- 0 . 7 0 3}$ & $\mathbf{0 . 9 8 9}$ & 0.106 & $\mathbf{- 0 . 7 3 7}$ \\
Cond.tannins & -0.630 & 0.077 & 0.656 & $\mathbf{- 0 . 8 3 9}$ & 0.620 & -0.515 & -0.075 \\
Hydrol.tannins & $\mathbf{- 0 . 7 1 7}$ & -0.079 & $\mathbf{0 . 9 3 2}$ & $\mathbf{- 0 . 7 0 2}$ & $\mathbf{0 . 9 8 9}$ & 0.106 & $\mathbf{- 0 . 7 3 8}$ \\
Flavonoids & $\mathbf{- 0 . 8 1 6}$ & -0.008 & $\mathbf{0 . 9 2 0}$ & $\mathbf{- 0 . 8 9 3}$ & $\mathbf{0 . 9 2 5}$ & -0.240 & -0.467 \\
Alkaloids & -0.422 & -0.075 & $\mathbf{0 . 8 4 0}$ & -0.314 & $\mathbf{0 . 8 9 7}$ & 0.537 & $\mathbf{- 0 . 9 5 2}$ \\
Cyanides & 0.581 & 0.298 & $\mathbf{- 0 . 8 5 7}$ & 0.463 & $\mathbf{- 0 . 9 1 9}$ & -0.339 & $\mathbf{0 . 8 3 1}$ \\
Phytates & $\mathbf{0 . 7 8 2}$ & -0.069 & $\mathbf{- 0 . 9 1 6}$ & $\mathbf{0 . 9 1 3}$ & $\mathbf{- 0 . 9 0 2}$ & 0.290 & 0.420 \\
Carotenoids & $\mathbf{- 0 . 7 2 9}$ & 0.074 & $\mathbf{0 . 9 5 7}$ & $\mathbf{- 0 . 8 6 0}$ & $\mathbf{0 . 9 2 8}$ & -0.197 & -0.495 \\
\hline
\end{tabular}

The correlations in bold character statistically are significant at $\alpha=0.05$. Insol $=$ insoluble ; cond $=$ condensed; hydrol = hydrolysable; DPPHH = 1,1-diphenyl-2-picrylhydrazyl (reduced); FIRA = Ferric Iron Reducing Activity; HRSA = Hydroxyl Radical Scavenging Activity. 
In accordance with the previous view, the graph of different variables on the principal component axis and the biplot of different powders and variables on the principal component axis are illustrative. The axis PC1 and PC2 support the most of information cumulated at $90.62 \%$. Therefore, the eigen values of principle components are significant for PC1 and PC2 (Table 3).
All parameters are well distributed on or in the correlation circle, except the non-significant ones such as FIRA (Fig. 4). The biplot of different powders and variables on the principal component (Fig. 5) show the relationship between secondary metabolites and their functional activities.

TABLE 3

Eigen values of principle components (PC).

\begin{tabular}{lcccccccc}
\hline & PC1 & PC2 & PC3 & PC4 & PC5 & PC6 & PC7 & PC8 \\
& & & & & & & & \\
\hline Eigen value & 12.417 & 4.801 & 1.158 & 0.355 & 0.180 & 0.057 & 0.024 & 0.009 \\
\% variance & 65.350 & 25.270 & 6.096 & 1.869 & 0.946 & 0.299 & 0.125 & 0.045 \\
\% cumulated & 65.350 & 90.620 & 96.716 & 98.585 & 99.531 & 99.830 & 99.955 & 100.000 \\
& & & & & & & & \\
\hline
\end{tabular}

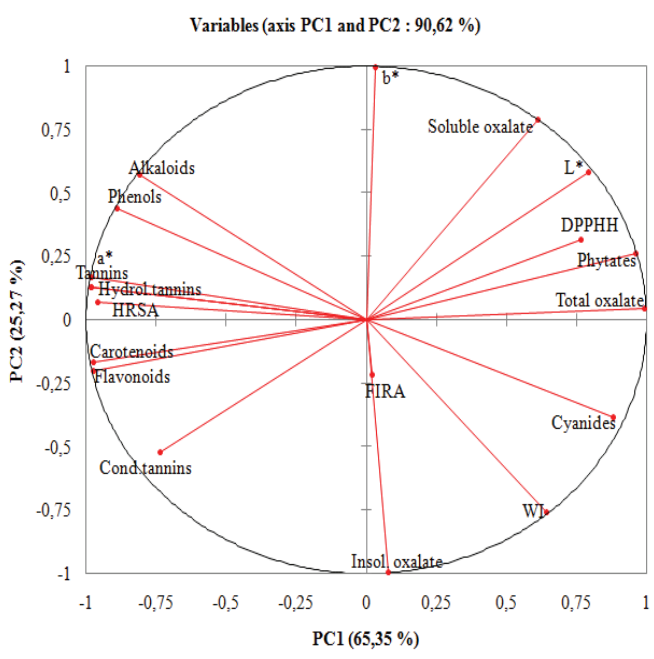

Fig. 4: Graph of different variables on the principal component axis.

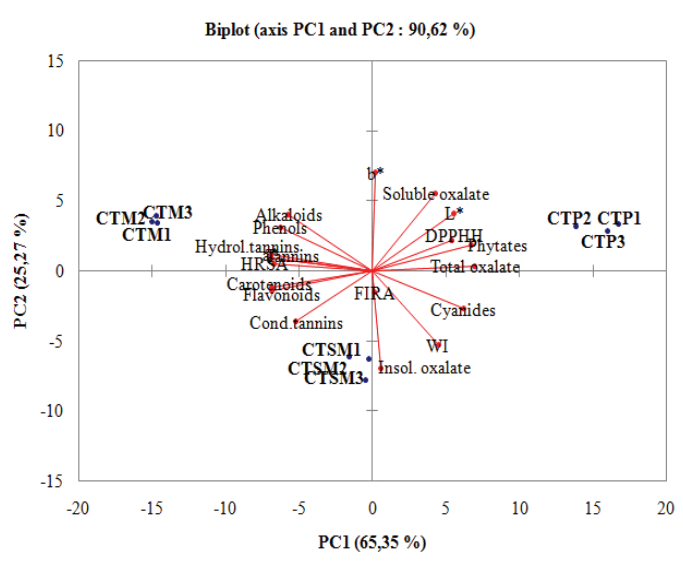

Fig. 5: Graph of different powders and variables on the principal component axis (the different powders are represented by bold points). 


\section{Conclusion}

The Cochlospermum tinctorium root contains many secondary metabolites that play important role as antioxidant and anti-reactive oxygen species. Its compounds are potent to heal or correct many disorders caused in cellular compartments such as mitochondria. The ability of C. tinctorium root extract in giving hydrogen to neutralize free radicals enhances its application in multiple ways. Meanwhile, further investigations are necessary to facilitate a usage of the C. tinctorium.

This study was carried out a collaborative research between ENSAI of the University of Ngaoundere (cameroon), and LIBIO of INPL of Nancy-University (France) and the Faculty of Exact and Applied Sciences of the University of N'Djamena (Chad). We are grateful for such a collaboration.

\section{References}

Abdou Bouba, A., Nintang Y. N., Scher J. \& MboFunG, C. M. F. (2010) Phenolic compounds and radical scavenging potential of twenty Cameroonian spices. Agric. Biol. J. N. Am. 1 (3), 213 $-224$.

Abdou Bouba, A., Nintang, N. Y., Foyet, H. S., Scher, J., Montet, D. \& Mbofung C. М. F. (2012) Proximate Composition, Mineral and Vitamin Content of Some Wild Plants Used as Spices in Cameroon. Food and Nutr. Sci. 3, 423 - 432.

Adeniyi, S. A., Orjekwe, C. L. \& Ehiagbonare, J. E. (2009) Determination of alkaloids and oxalates in some selected food samples in Nigeria. African J. Biotech. 8 (1), 110 - 112.

Ahmadu, R. O., Kogi, E. \& Ndams, I. S. (2014) Antiplasmodial Activity of the Root Extracts of Cochlospermum tinctorium in Mice Experimentally Infected with Clinical Isolates of Plasmodium berghei (NK 65). British Journal of Pharmaceutical Research 4 (8), 895 - 909.
Ahmed, T. S., Magaj, M. G., Yaro, A. H., Musa, A. M \& Adamu A. K. (2011) Aqueous methanol extracts of Cochlospermum tinctorium (A. Rich) possess analgesic and anti-inflammatory activities. Pharmacology 3 (3), 237 - 242.

Ahmed, T. S., Magaj, M. G., Yaro, A. H., Musa, A. M. \& Adamu, A. K. (2011) Aqueous methanol extracts of Cochlospermum tinctorium (A. Rich) possess analgesic and anti-inflammatory activities. Pharmacology 3 (3), 237 - 242.

Akinloye, O. A. \& Ayankojo, A. G. (2011) Hepatoprotective activity of Cochlospermum tinctorium against carbon tetrachloride induced hepatotoxicity in rats. Agric. Biol. J. N. Am. 2 (9), 1283 -1288 .

Akinloye, O. A., Ayankojo, A. G. \& Olaniyi, M. O. (2012) Hepatoprotective activity of Cochlospermum tinctorium against carbon tetrachloride induced hepatotoxicity in rats. Rom. $J$. Biochem. 49 (1), 3-12.

Auldridge, M. E., Mccarty, D. R. Klee, H. J. (2006) Plant carotenoid cleavage oxygenases and their apocarotenoid products. Current Opinion in Plant Biology 9, 315 - 321.

Benoit, F., Valentin, A., Pelissier, Y., Marion, C., DaKuYo, Z., Mallie, M. \& BAStide, J. M. (1995) Antimalarial activity in vitro of Cochlospermum tinctorium tubercle extracts. Transactions of the Royal Society of Tropical Medicine and Hygiene 89 (2), 217 - 218.

Ekanem, J. O. (1994) Treatment regimens for malaria as a function of level of chemo-resistance in Africa Malaria/Paludisme et maladies infectieuses 1, 96 - 97 .

Eom, S. H., Cheng, W. J., Hyoung, J. P., Kim, E. H., Chung, M. I., Kiм, M. J., Yu, C. \& Chо, D. H. (2007) Far infra red ray irradiation stimulates antioxidant activity in Vitis flexuosa Thunb. Berries. Kor. J. Med. Crop Sci. 15, 319 - 323

Etuk, E. U., Agaie, B. M., Ladan, M. J. \& Garba, I. (2009A) The modulatory effect of Cochlosper- 
mum tinctorium a rich aqueous root extract on liver damage induced by carbon tetrachloride in rats. Afr J. Pharm Pharmacol 3, 151 - 157.

Etuk, E.u., Francis, U. U. \& Garba, I. (2009B) Regenerative action of Cochlospermum tinctorium aqueous root extract on experimentally induced hepatic damage in rats. African Journal of Biochemistry Research 3 (1), 001 - 004.

Guiguemde, W. A., Nikiema, J. P., Tinto, H. \& Guissou, I. P. (2000). Contribution à l'identification des principes antiplasmodiques de Cochlospermum tinctorium A. Rich. (Cochlospermaceae). Faculté des sciences de la santé, Université de Ouagadougou, thèse en pharmacie $\mathrm{n}^{\circ} 15,88 \mathrm{p}$.

Harborne, J. B. (1973) Phytochemical Methods, Chapman and Hall, London, pp. 11-21.

Jose, S. \& Radhamany, P.m. (2012) Identification and determination of antioxidant constituents of bioluminescent mushroom. Asian Pac J. Trop Biomed 2, S386 - S391.

Magaj, M. G., Shehu, A., Musa, A. M., Sani, M. B. \& Yaro, A .H. (2010) Pharmacological evidence on the folkloric use of Cochlospermum tintorium A. Rich. in the management of diarrhea. Int. J. Pure. Appl. Sci. 4, 14 - 20.

Maina, B. B., Magaji, M. G., Yaro, A. H., Hamza, A. H., Ahmed, S. T. \& MagaJ, R. A. (2009) Anticonvulsant studies on Cochlospermum tinctorium and Paullinia pinnata extracts in laboratory animals. Nig. J. Pharm. Sci. 8 (1), 102 - 108.

Mbaebie, B. O., Edeoga, H. O. \& Afolayan, A. J. (2012) Phytochemical analysis and antioxidants activities of aqueous leaf bark extract of Schotia latifolia Jacq. Asian Pac J. Trop Biomed 2, 118 - 124.

Ndouyang, C. J., Himeda, M. \& Nguimbou, R. M. (2018) Antinutriments et propriétés nutritionnelles in vivo de Cochlospermum tinctorium A. Rich. (Bixaceae) chez les jeunes rats (Rattus norvegicus L.). Int. J. Biol. Chem. Sci., 12 (2), $884-901$.
Ndouyang, C. J ., Nuintang, Y. N., Facho, B., Scher, J. \& Mbofung, C. M. F. (2015) Effect of Processing Method on the Antinutrient Content of Tacca leontopetaloides (L.) Kuntze Flour. British Journal of Applied Science \& Technology $\mathbf{5}$ (3), $258-269$.

Nergard, C.s., Diallo, D., Innguerdingen, K., Michaelsen, T.e., Kiyohara, H., Yamada, H. \& Paulsen, B. S. (2005) Medicinal use of Cochlospermum tinctorium in Mali: Anti-ulcer, radical scavenging and immunomodulating activities of polymers in the aqueous extract of the roots. J Ethnopharmacol. 96, 255 - 269.

Ouattara, L., Koudou, J., Obame, L. C. E., Karou, D.s., Traore, A. \& Bessiere, J.M. (2007). Chemical Composition and Antibacterial Activity of Cochlospermum planchoni Hook.f. ex Planch Essential Oil from Burkina Faso. Pakistan Journal of Biological Sciences 10, 4177 4179.

Oyaizu, M. (1986) Studies on products of browning reaction: antioxidative activity of products of browning reaction. Japanese J. Nutr. 40, 307 -315 .

Rainha, N ., Lima, E., Baptista, J. \& Rodrigues, C. (2011) Antioxidant properties, total phenolic, total carotenoid and chlorophyll content of anatomical parts of Hypericum foliosum. J. Med. Plant. Res. 5 (10), 1930 - 1940.

Sakthidevi, G. \& Mohan, V. R. (2013) Total Phenolic, Flavonoid Contents and In vitro Antioxidant Activity of Dioscorea alata L. Tuber. J. Pharm. Sci. \& Res. 5 (5), 115 - 119.

Sanmugapriya, E. \& Venkataraman, S. (2006). Studies on the hepatoprotective and antioxidant actions of Strychnos potatorum Linn seeds on CCl4 induced hepatic acute injury in experimental rats. J. Ethnopharmacol. 105, 154-160.

Solon, S., Carollo C. A. \& Brandẽo, L. F. G. (2012) Phenolic derivatives and other chemical compounds from Cochlospermum regium. Quim. Nova, 35 (6), 1169 - 1172. 
SonnergaArd, J. M. (1999) A critical evaluation of the Heckel equation. International Journal of Pharmaceutics 193, 63 - 71.

Tidjani, M. B., Bello, I. A., Aliyu, A. B., Olurishe, T. \& Maidawa, S. M. (2009) Phytochemical and antibacterial studies of root extract of Cochlospermum tinctorium A. Rich. (Cochlospermaceae).Research Journal of Medicinal Plant 3 (1), $16-22$.

Tiné, F., Liberati, A., Craxi, A., Almasio, P. \& PagliaRO, L. (1993) Interferon treatment in patients with chronic hepatitis B: a meta-analysis of the published literature. J Hepatol, 18, 154 - 162.

Tsai, L. J. (1994) Research and development of extrudates containing porcine blood. Master thesis, Graduate Institute of Food Science and Technology, National Taiwan University, Taiwan.

Villaño, D., Fernández-Pachón, M. S., Moyá, M. L., Troncoso, A. M. \& Garcia-Parrilla, M. C. (2007) Radical scavenging ability of polyphenolic compounds towards DPPH free radical. Talanta 71, 230-235.
Zederkopff-Ballin, N., Traore, M., Tinto, H., Sittie, A., Molgaard, P., Olsen, C. E., Kharazmi, A. \& Christensen, S. B. (2002) Antiplasmodial compounds from Cochlospermum tinctorium. Journal of Natural Products 65 (9), 1325 1327.

Zhang, D. \& Yasumori, H. (2004) Phenolics. Ascorbic Acid Carotenoïds And Antioxidant Activity Of Broccoli, And Their Changes During Conventional And Microwave Cooking, Food Chem. 88, 503 - 509.

Zhang, T., Li, S. Y., Converse, P. J., Grosset, J. H., Nuermberger, E. L. (2013) Rapid, Serial, Non-Invasive Assessment Of Drug Efficacy In Mice With Autoluminescent Mycobacterium Ulcerans Infection. Plos Negl. Trop. Dis., 7 (12), E2598.

Received 11 Oct 18; revised 27 Nov 18. 